\title{
Democratizar é Preciso, Municipalizar não é Preciso
}

José Marcelino de Rezende Pinto

FFCLRP - USP

\section{Resumo:}

Neste artigo pretendemos apresentar um modelo de gestão dos recursos financeiros no ensino fundamental, construldo a partir de uma crítica ds atuais propostas de municipalização e de um diagnóstico das principais falhas e pontos de estrangulamento do modelo de gestão em vigor.

Buscaremos apresentar neste trabalho uma proposta de administração do ensino fundamental que seja uma alternativa concreta à municipalização deste nível de ensino que está sendo implementada a toque de caixa pelos executivos estaduais à revelia dos seus colegas municipais ( como exemplo, basta dizer que $30 \%$ dos municípios paulistas já assinaram convênios de municipalização) o que, a nosso ver, levará à degradação completa do único grau de ensino a que a maioria da população tem acesso.

Em primeiro lugar, vamos indicar os principais motivos que nos levam à crítica da municipalização.

\section{A Rede de Ensino Municipal}

A rede municipal brasileira, longe de ser um exemplo de força dos municípios mais fortes e ricos da federação, é antes de tudo um sintoma de fraqueza de estados mais pobres que, pelo seu descompromisso com o ensino, obrigam seus paupérrimos municípios a assumí-lo. Assim, a rede municipal de primeiro grau que, a nível de Brasil, responde por $1 / 3$ do total de matrículas, participa no Nordeste com a metade das vagas neste grau de ensino, enquanto no Sudeste sua participação é de apenas 1/4. Particularmente no Estado de São Paulo, o mais rico da federação, ela representa apenas $1 / 10$ do total de vagas. Ademais, é uma rede essencialmente rural ( $74 \%$ da matrículas neste meio ) e feita em estabelecimentos de uma sala ( $77 \%$ do total ). Quanto à qualidade do ensino oferecido, basta dizer que o nível de formação da metade dos seus professores não vai além do $1^{\circ}$ grau completo ( $32 \%, 1^{\circ}$ grau incompleto, no $\mathrm{Ne}$, $50 \%$ ). A rede municipal apresenta ainda os piores indicadores de evasão escolar, repetência, relação professor/aluno e distorção série-idade. Quanto aos salários, $73 \%$ dos municípios pagam até 1 salário-mínimo ( $56 \%$ pagam menos que $1 \mathrm{SM}$ ), não sendo difícil encontrarmos salários equivalentes a 1/10 do mínimo legal. Deve-se ainda acrescentar que a maioria dos municípios não realizam concurso público para o preenchimento dos cargos de sua rede e os planos de carreira, quando existentes, são descumpridos.

Paidéia, FFCLRP - USP, Rib. Preto, 3, Ago/Jan, 1993. 


\section{As Finanças Municipais}

Vejamos agora como se encontram as finanças municipais. Apesar da reforma tributária efetuada pela nova Constituição Federal, o município ainda é o nível de governo mais desguarnecido de recursos. De maneira geral, as projeçōes indicam que, na melhor das hipóteses, os municípios deverão fícar com $24 \%$ do bolo fiscal, contra $42 \%$ para os estados e $34 \%$ para a união. Para podermos aquilatar o impacto financeiro da municipalização do ensino de $\mathbf{l}^{\mathbf{2}}$ grau, basta dizer que os recursos atualmente mobilizados por este nível de ensino representam o equivalente a $70 \%$ da receita líquida de impostos dos municípios, ou 2 vezes sua receita tributária e a 5 vezes os seus gastos com educação . Assim, mesmo supondo a transferência de recursos dos níveis superiores de governo ( que, como a história tem seguidamente mostrado, não sói ocorrer e, quando ocorre, se dá apenas no $\mathbf{l}^{\mathbf{Q}}$ ano de implantação dos convênios como foi o caso da merenda escolar ) a municipalização se mostra inviável do ponto de vista administrativo dado o montante elevado de recursos que prefeituras que, em sua maioria, nem possuem secretarias de educação, deverão administrar. Nunca é demais lembrar que $78 \%$ dos municípios brasileiros possuem menos de 25.000 habitantes, e $97 \%$ menos de 100.000 hab. Por sua vez, a alternativa híbrida de que os estados estão se valendo ( municipaliza-se apenas parte dos serviços educacionais, dependendo do grau de aquiescência da administração municipal ) é, a nosso ver, a pior de todas pois mascara as responsabilidades e transforma um problema global em casos individuais, na medida em que os contratos são firmados pelos estados, município a município. Isto sem falar no estímulo inestimável que estes contratos abrem para o clientelismo político. Alguém tem a ilusão de que o governo estadual vai repassar recursos na quantia e no tempo necessários para um prefeito da oposiçăo ? Para concluir esta linha de argumentos, é importante que fique claro o seguinte : NENHUM município brasileiro, rico ou pobre, tem condiçōes financeiras de assumir toda a rede de ensino fundamental.

E com base nestes fatos e argumentos que temos a plena convicção de que, quem oferece os piores serviços em educação e é o mais pobre dos níveis de governo, não tem a menor condição de assumir um grau de ensino que responde por $76,5 \%$ das matrículas, o equivalente a 27,6 milhões de brasileiros.

\section{O DESPERDICIO DE RECURSOS}

Um segundo aspecto que logo salta aos olhos quando se analisa a administração da educação pública no Brasil é a constatação de seguidos desperdícios de recursos aliados a uma total falta de prioridades na sua aplicação. Vamos a alguns exemplos :

- Apesar da Constituição Federal determinar que pelos menos a metade dos recursos destinados pelos poderes públicos à educação deve ser aplicada no ensino fundamental e na erradicação do analfabetismo nos primeiros 10 anos após a sua promulgação, o orçamento do Uniāo para o ano de 1990 ( que foi "discutido" e aprovado em menos de 1 hora pelo mesmo congresso que 
elaborou a Constituição ) destinou apenas $12,7 \%$ dos recursos da educação para este nível de ensino;

- Segundo estudos do Banco Mundial de cada 100 dólares destinados ao Nordeste, apenas a metade chega à sala de aula;

- A FAE ( Fundação de Amparo ao Estudante ) responsável pela compra e distribuição da merenda e material didático, não sai do noticiário, constantemente envolvida em denúncias de fraudes, dando um trabalho imenso ao TCU;

- De uma maneira geral, quanto mais rico um município, menor tem sido a participação da rede municipal no total de matrículas, ao contrário do que seria mais desejável e justo;

- A relação Pessoal Docente/Pessoal Não Docente é próxima de 1 na maioria dos estados das regiōes Norte, Nordeste e Centro-Oeste. Além disso, não é difícil encontrarmos em redes municipais ou estaduais, estabelecimentos de ensino de 1 sala, onde os gastos com pessoal não docente são superiores àqueles com pessoal docente;

- Os estados dos Nordeste gastam em suas redes de segundo grau o mesmo volume de recursos dos estados do Sudeste apesar de possuirem menos da metade do nú:nero de alunos e, proporcionalmente, gastam 2,5 vezes mais recursos com "Administração";

- Usando uma série de artifícios contábeis a União, os estados e municípios acabam por aplicar efetivamente em Manutenção e Desenvolvimento do Ensino índices muito inferiores àqueles definidos constitucionalmente;

- Aplicando-se os percentuais definidos pela Constituição Federal e priorizando-se o ensino fundamental é plenamente possível garantir-se uma remuneração média de 5 Salários-Mínimos por uma jornada semanal de 20 horas para todos os professores de $\mathbf{l}^{\mathbf{0}}$ grau do país, valor muito superior ao atualmente praticado.

Frente a estes rápidos mas significativos exemplos que să̈o uma gota num oceano de inépcia e incúria administrativa, é que somos tentados a desenvolver um modelo que ataque de frente a irracionalidade que é a existência simultânea de três redes públicas diferentes para um mesmo grau de ensino, com a consequente dispersão dos recursos, sem contudo destruirmos o pouco que resta de qualidade do ensino, que seria a consequência natural da municipalização. Vamos então à proposta.

Partindo, da constatação da necessidade de integração das redes existentes, tomaremos contudo como base de referência a rede estadual, ao contrário da municipal, na medida em que ela responde por $2 / 3$ dos alunos das escolas públicas de ${ }^{l}$ grau e apresenta padrões razoáveis de qualidade, além de 
já dispor de todo o aparato técnico e de pessoal para o gerenciamento deste nível de ensino. Assim as unidades de gerenciamento do ensino fundamental ( e médio, se for o caso ) seriam as DIVISÓES REGIONAIS DE ENSINO ( ou equivalentes ) que obrigatoriamente se transformariam em autarquias (estaduais ou federais, com preferência para estas últimas como forma de comprometer a União com este grau de ensino ) como as universidades e seriam responsáveis por todos os alunos e estabelecimentos da região sob sua competência territorial. Teriam então autonomia administrativa e financeira, sendo os recursos, advindos dos 3 níveis de governo, recebidos na proporçāo do número de alunos matriculados, com base em padrōes de custo-aluno para os diferentes tipos de escolas atendidas, em valores atualizados monetariamente. Estas unidades gozariam ainda de capacidade jurídica para executar o nível de governo inadimplente e, $o$ mais importante, seriam controladas por um conselho diretor eleito pela comunidade escolar. Concomitantemente haveria um plano de carreira para os trabalhadores do ensino nacionalmente unificado, com regime jurídico único ( a exemplo das universidades federais ) e piso salarial fixado através de lei votada pelo congresso nacional. Um primeiro passo no sentido de testar a implantação desta proposta seria a transformação das atuais Secretarias de Educação em autarquias com repasse automático de recursos conforme o modelo a seguir :

\section{ESQUEMA}

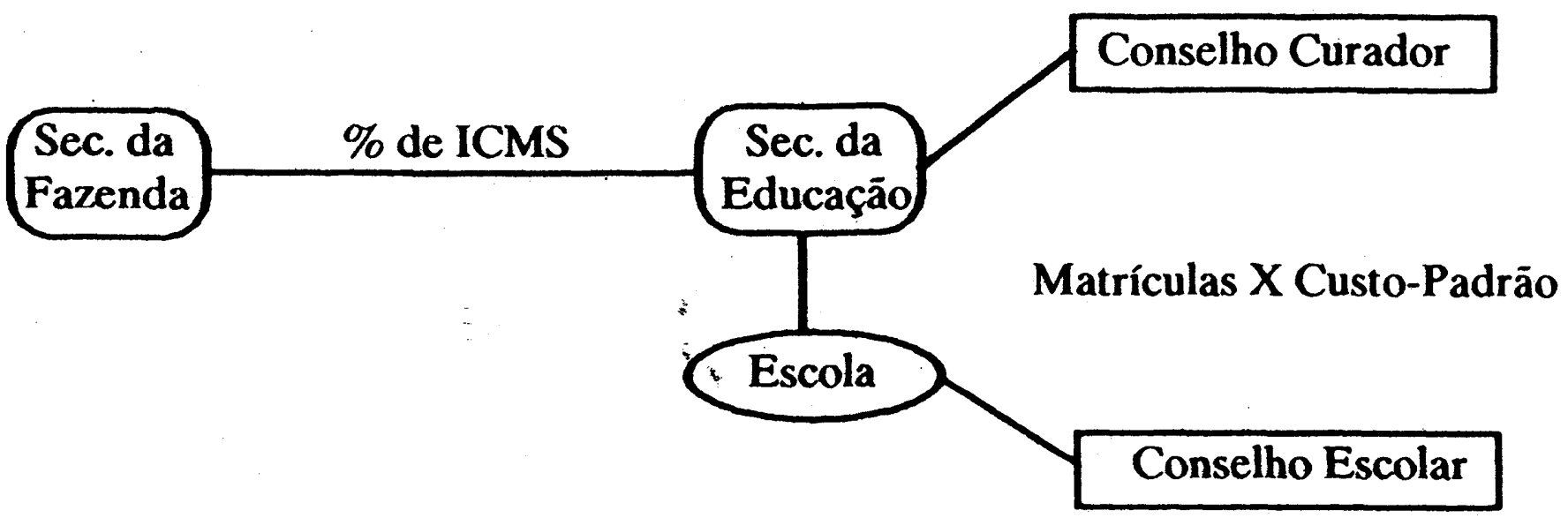

Estes são, em síntese, os pontos principais do modelo, que, acreditamos, pode abrir um campo novo nos debates que se travam em torno da questão da administração do ensino, superando a polarizaçāo maniqueísta em cima da municipalização. Por outro lado, temos plena consciência que, antes de técnica, esta é uma questão política, pois envolve o poder de nomear ou demitir milhares de pessoas e de ( pensa-se ) manipular a cabeça dos futuros eleitores. Contudo, se a saída do atual impasse em que se encontra a educação é política e passa pela conscientização dos cidadãos de que, em educação, o que importa não é só quantidade, mas esta aliada à qualidade, é fundamental apontar-se uma dimensão técnica que permita que o anseio geral de eficiência e eqüidade na 
gestão da coisa pública, se coadune com os preceitos democráticos nas tomadas de decisão. É neste contexto que nossa proposta se insere.

\section{Bibliografia Básica :}

DAVIES, Nicholas. Municipalização do Ensino : Caminho para Democratização Revista Tecnologia Educacional, Rio de Janeiro, 20 (101): 36-47, Jul/Ago, 1991.

MAIA, Eny Marisa. A Municipalização do Ensino em Processo: A Experiência do Estado de São Paulo. Revista ANDE, São Paulo, 16: 10-16, 1990.

MELCHIOR, José Carlos de Araújo. Financiamento da Educação: Gestão Democrática dos Recursos Financeiros Públicos em Educação. In Ensino Médio como Educação Básica. São Paulo, Cortez-SENEB, 1991.

PINTO, José Marcelino de Rezende. As Implicações Financeiras da Municipalização do Ensino de Primeiro Grau. Campinas, 1989, 204 p. Dissertação ( mestrado ). Faculdade de Educação da UNICAMP.

ROMĀO, José Eustáquio. O Financiamento da Educação Fundamental no Município. Revista Tecnologia Educacional, Rio de Janeiro, 20 (101) 36-47, Jul/Ago, 1991.

VELlOSO, Jacques. O Público e o Privado no Projeto de LDB: Organização, Gestão e Recursos do Ensino. In Lei de Diretrizes e Bases da Educação Nacional. São Paulo, Cortez-ANDE, 1990.

\section{ABSTRACT}

Democracy is necessary, local run of education is not

It's our aim to present in this paper, a management model of Brasilian elementary education resources. The management model was based on a critc review of current approaches to local run of elementary school, and also based on a diagnosis of the main problems of present educational resources management. 